\title{
Successful completion of pregnancy after mustard procedure for transposition of great arteries: A rare case from the developing world
}

Muhammad Kamran Younis Memon

Aga Khan University

Ayesha Malik

Aga Khan University, ayesha.malik@aku.edu

Saleem Akhtar

Aga Khan University, saleem.sadqani@aku.edu

Follow this and additional works at: https://ecommons.aku.edu/

pakistan_fhs_mc_women_childhealth_paediatr

Part of the Cardiology Commons, Obstetrics and Gynecology Commons, and the Pediatrics Commons

\section{Recommended Citation}

Younis Memon, M. K., Malik, A., Akhtar, S. (2020). Successful completion of pregnancy after mustard procedure for transposition of great arteries: A rare case from the developing world. JPMA. The Journal of the Pakistan Medical Association, 70(5), 920-922.

Available at: https://ecommons.aku.edu/pakistan_fhs_mc_women_childhealth_paediatr/894 


\section{Successful completion of pregnancy after Mustard procedure for transposition of great arteries: a rare case from the developing world}

Muhammad Kamran Younis Memon'1, Ayesha Malik2', Saleem Akhtar ${ }^{3}$

\begin{abstract}
Surgical repair of transposition of great arteries has undergone various evolutionary changes over the years. The initial of these treatment options was atrial septectomy followed by atrial switch and the current preferred treatment option is arterial switch operation worldwide. Due to various reasons, like lack of medical and surgical expertise atrial switch operation was commonly in practice in developing countries until few years back. Pregnancy in a patient with history of atrial switch operation poses a unique haemodynamic challenge. We report the case of a successful pregnancy in a 26 years old lady who had undergone Mustard repair surgery in the past in Pakistan.
\end{abstract}

Keywords: TGA, Mustard operation, Pregnancy, Congenital heart disease

\section{https://doi.org/10.5455/JPMA.22875}

\section{Introduction}

Surgical repair of transposition of great arteries (TGA) has undergone great evolution over years. The first landmark in this journey was the introduction of atrial septectomy by Alfred Blalock and his assistant Hanlon;' followed by intra atrial repair of TGA by Mustard and Senning ${ }^{1}$ and Jatene procedure later on. Mustard procedure involved creating an intra-atrial baffle (made of synthetic material) which directs systemic venous return to left atrium and pulmonary venous return to right atrium. Senning procedure involved same principle but here intra atrial tissue is used to create baffle. ${ }^{2}$ Both Mustard and Senning procedure have largely been replaced by arterial switch procedure except for few indications. ${ }^{3}$ Long term complications after Mustard procedure can be heart failure, arrhythmias, pulmonary oedema, systemic and pulmonary venous baffle obstruction and leaks. Haemodynamic changes during physiologic conditions like pregnancy may exacerbate these complications and can be fatal in

1,3Department of Pediatrics, Aga Khan University Hospital Karachi, Pakistan; 2Department of Obstetrics and Gynaecology, Aga Khan University Hospital, Karachi, Pakistan.

Correspondence: Muhammad Kamran Younis Memon. e-mail:mkam81@gmail.com the patient population. ${ }^{4}$ To the best of our knowledge, this case is the first report of successful pregnancy in a 26 years old lady who underwent Mustard repair surgery in a developing country like Pakistan.

\section{Case Report}

A 26 years old woman was referred by obstetrics department to Paediatric Cardiology department at Aga Khan University hospital for a foetal echocardiogram in February 2018. She was 24 weeks pregnant and was followed by general physician and obstetrician. She had a very bad obstetric history with 5 previous abortions. The indication for foetal echocardiogram was history of congenital heart disease in the mother and bad obstetric history. On probing the history, she disclosed that she had some surgery done at 3 years of age and was doing fine after that surgery. She was unaware of her exact illness due to her poor educational background. We requested her to bring her previous record which was fortunately available and it revealed that she had undergone Mustard procedure at the age of three years. Since then she did not consult any doctor and was not on any medications. At the time of presentation, she was asymptomatic and NYHA functional class 1-2. She was haemodynamically stable and her examination showed mild right parasternal heave with normal heart sounds and no significant murmur was audible. So, we decided to continue to follow her closely in collaboration with our neonatology and obstetric colleagues. Her echo (Figure 1,2 and 3) showed normal LV functions mild systemic ventricle (Right Ventricle) dysfunction, dilated hypertrophied right ventricle, non-obstructed systemic and pulmonary venous baffle obstruction and mild to moderate tricuspid valve regurgitation. Her foetal echo was normal. We did 24 hours Holter monitoring on her which was normal except for intermittent ectopic atrial activity and occasional unifocal PVC's. Plan was to continue to follow her and if she remains asymptomatic, deliver the baby at term. She developed gestational diabetes so was started on insulin injections. She was monitored on fortnightly basis in cardiology and obstetrics clinic. She presented with shortness of breath 


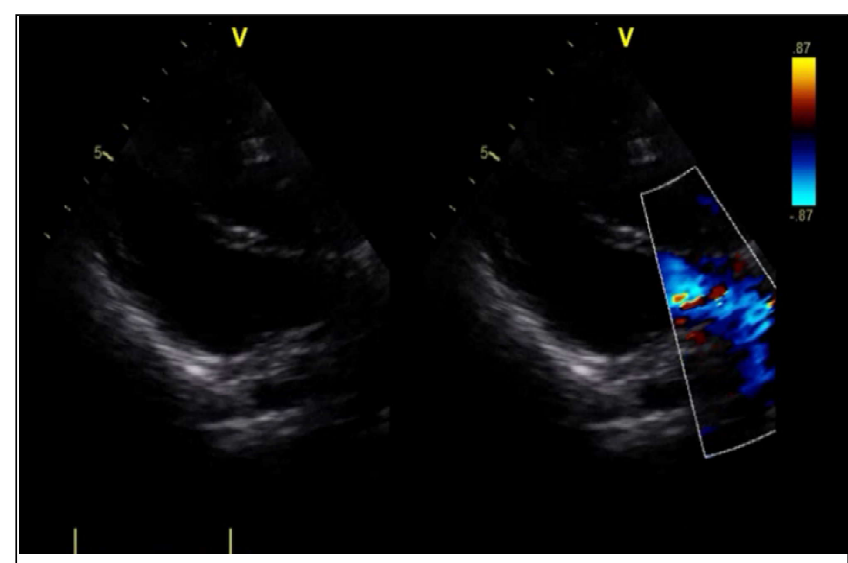

Figure-1: Parasternal long axis view, showing pulmonary artery (PA) arising from left ventricle (LV). Right ventricle (RV).

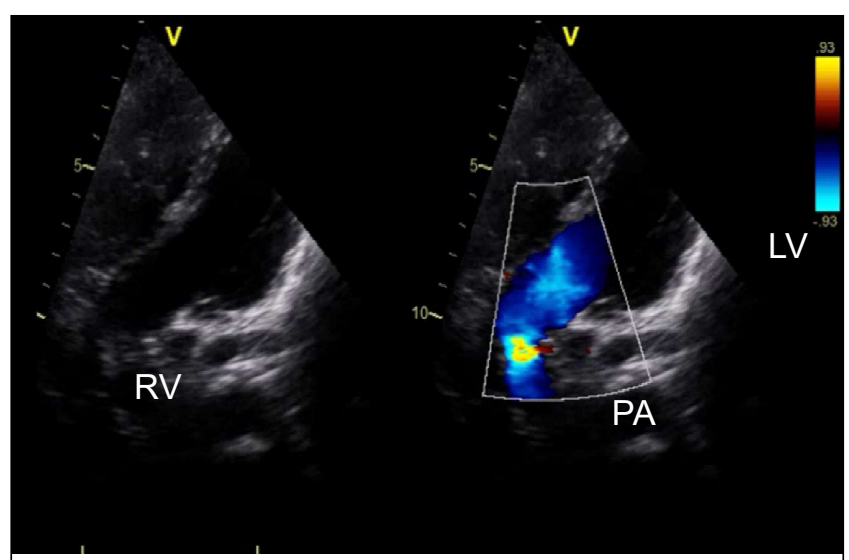

Figure-2: Modified five chamber view, showing pulmonary artery (PA) arising from left ventricle (LV).

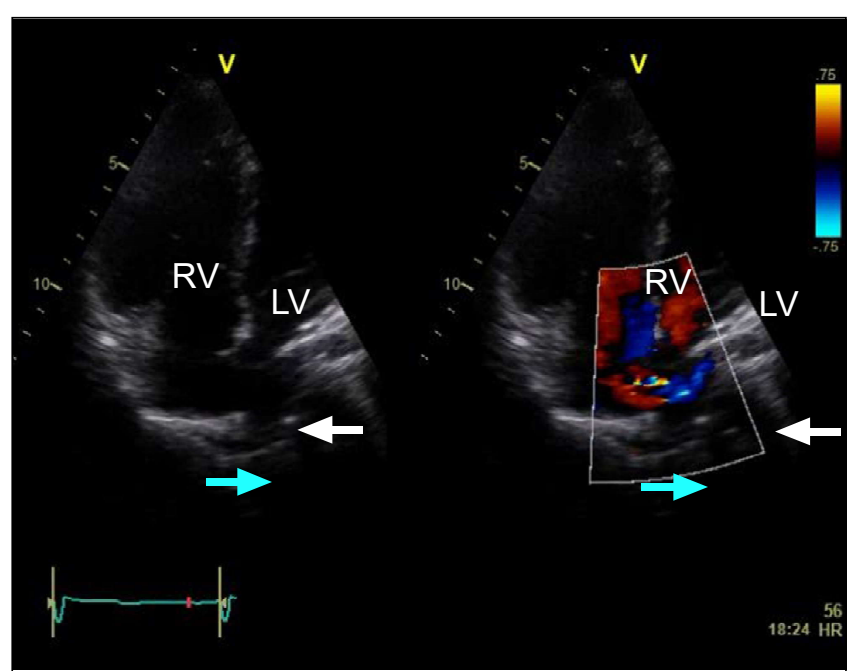

Figure-3: Four chamber view showing pulmonary venous baffle (blue arrow), and systemic venous baffle (white arrow) without any obstruction, right ventricle (RV), left ventricle (LV). at 27 weeks of pregnancy which responded to furosemide treatment. She remained asymptomatic and her pregnancy was progressing well except that she developed polyhydramnios, so the pregnancy was continued with close follow-up. She persistently had reduced foetal movements increasing her chances of a stillbirth so during 34 + weeks gestation she was electively admitted for lower caesarean section. She delivered a healthy baby girl weighing $2.3 \mathrm{~kg}$ with good Apgar. The Patient was asymptomatic with an unremarkable ECHO post pregnancy.

\section{Discussion}

This Case report confirms that atrial level repair of TGA although not a good treatment option because of the complications associated with the procedure, but still with good medical follow up, successful pregnancy can still be achieved relatively safely. Reported survival for patients with Mustard repair at 10 and 30 years is 84 to $91 \%$ for simple TGA respectively and 76 to $86 \%$ for 10 to 25 years for patients with complex TGA. 5

In developing countries like Pakistan where medical facilities for congenital heart disease are generally not very good, even if one gets treatment, medical follow ups are very rare entity, which makes the overall management of these patients very difficult.

Physiological changes during pregnancy poses a unique challenge to systemic ventricle in patients with atrial level repair. The pregnancy in these patients is generally well tolerated. 6 The haemodynamic changes known to occur during pregnancy, like, $40-50 \%$ increase in blood volume, increase in heart rate by 10 to 20 beats per minute, decreased systemic vascular resistance (SVR) and pulmonary vascular resistance (PVR), result in 30-50\% increase in cardiac output. ${ }^{4}$ So systemic ventricle which is RV in this scenario is prone to fail with this increase in demand.

Risk of congenital heart disease in offspring's of mothers with transposition is unknown, although mothers with congenital heart disease are at greater risk than general population to have offspring with congenital heart disease, which some studies reported the incidence to vary between $2 \%$ to $18 \% .^{7}$

With increasing age systemic ventricular dysfunction becomes increasingly common. Other complications such as arrhythmia, tricuspid valve regurgitation, pulmonary 
or systemic venous baffle obstruction and sub pulmonary stenosis also become increasingly evident with increasing age. 8

Developing countries like Pakistan where lack of medical infrastructure makes management of these patients with congenital heart disease very difficult. Even if somehow, they get treatment, lack of proper follow up makes their long-term management very difficult and usually these patients again come to medical attention with other complications. These patients need multidisciplinary treatment to look after these complications. As far as our patient is concerned, she presented to us at 24 weeks of gestation with no previous follow up with any cardiologist with bad obstetric history of four miscarriages and one intrauterine death. Fortunately, she was clinically good at presentation andwe kept her on close follow up.She remained asymptomatic except for the brief duration of shortness of breath at 27 weeks gestation which responded well to treatment with furosemide. She delivered a healthy baby girl through Caesarean section at 34+ weeks gestation. Successful completion of pregnancy in treated patients with complex congenital heart disease like TGA is rarity in countries like Pakistan.

To our knowledge this is the first case of successful completion of pregnancy following Mustard repair for transposition of great arteries from a country like Pakistan, where medical facilities are slowly improving.

\section{Conclusion}

Patients with congenital heart disease need proper medical care even after repair. They should be in close follow up with the medical faculty where paediatric cardiologist should be available with experience of dealing with the unique complications in this patient population.

Consent: written and informed consent was taken from patient for all the procedure she underwent during her admission.

Disclaimer: None to declare.

Conflict of Interest: None to declare.

Funding Sources: None to declare.

\section{References}

1. Konstantinov IE, Alexi-Meskishvili VV, Williams WG, Freedom RM, Van Praagh R. Atrial switch operation: past, present, and future. Ann Thorac Surg 2004; 77: 2250-8.

2. Love BA, Mehta D, Fuster VF. Evaluation and management of the adult patient with transposition of the great arteries following atrial-level (Senning or Mustard) repair. Nat Clin Pract Cardiovasc Med 2008; 5: 454-67.

3. Drenthen W1, Pieper PG, Ploeg M, Voors AA, Roos-Hesselink JW, Mulder BJ; ZAHARA Investigators, et al. Risk of complications during pregnancy after Senning or Mustard (atrial) repair of complete transposition of the great arteries. Eur Heart J 2005; 26: 2588-95.

4. Sunman H, Canpolat U, Yorgun H, Gürgan T, Tokgözoglu L. Successful pregnancy by in vitro fertilization after Mustard operation for transposition of the great arteries. J Cardiol 2011; 3: e50-2.

5. Canobbio MM, Morris CD, Graham TP, Landzberg MJ. Pregnancy outcomes after atrial repair for transposition of the great arteries. Am J Cardiol 2006; 98: 668-72.

6. Cataldo S, Doohan M, Rice K, Trinder J, Stuart AG, Curtis SL. Pregnancy following Mustard or Senning correction of transposition of the great arteries: a retrospective study. BJOG 2016; 123: 80713.

7. Clarkson PM, Wilson NJ, Neutze JM, North RA, Calder AL, BarrattBoyes BG. Outcome of pregnancy after the Mustard operation for transposition of the great arteries with intact ventricular septum. J Am Coll Cardiol 1994; 24: 190-3.

8. Trigas V, Nagdyman N, Pildner von Steinburg S, Oechslin E, Vogt $M$, Berger F, et al. Pregnancy-related obstetric and cardiologic problems in women after atrial switch operation for transposition of the great arteries. Circ J 2014; 78: 443-9. 